\title{
A IMAGEM ECOLOGISTA DO PAPA FRANCISCO
}

\section{ARTIGO ORIGINAL}

DANTAS, José Erivaldo ${ }^{1}$

DANTAS, José Erivaldo. A imagem ecologista do Papa Francisco. Revista Científica Multidisciplinar Núcleo do Conhecimento. Ano 05, Ed. 08, Vol. 16, pp. 2437. Agosto de 2020. ISSN: 2448-0959, Link de acesso: https://www.nucleodoconhecimento.com.br/comunicacao/imagem-ecologista

\section{RESUMO}

Segundo Belting "todo ser humano é, naturalmente, um lugar das imagens" (BELTING, 2007, p. 71). É a partir desse lugar que o presente artigo busca compreender a Imagem ecologista do Papa Francisco, buscando traçar o lugar do Papa no mundo e sua representação nesse lugar, como imagem simbólica em relação à práxis pessoal e coletiva. Se para Belting as pessoas se diferenciam umas das outras por causa das imagens que carregam em seu próprio corpo, é possível afirmar que o Papa Francisco se diferencia dos demais papas por ser o primeiro Papa latinoamericano que traça o seu pontificado à luz das imagens culturais não totalmente europeias. As imagens que captamos no percurso da vida, deixam em nós uma marca invisível e indelével, de modo que não é possível agir sem estar referenciado por essas imagens, ainda que seja de forma invisível. Nesse sentido, o Papa Francisco não poderia agir de outra forma, se não a partir das imagens próprias do seu contexto cultural latino-americano, bem como, pelo seu onomástico, Francisco.

Palavras-chave: Imagens, lugar das imagens, imagem simbólica, Papa Francisco.

${ }^{1}$ Doutorando em Comunicação e Semiótica; Mestre em Ciências da Religião pela Pontifícia Universidade Católica de São Paulo - PUC; Licenciado em Filosofia pelo Centro Universitário Assunção - UNIFAl; Bacharel em Teologia pela Escola Dominicana de Teologia - EDT. 


\section{INTRODUÇÃO}

O presente artigo tem como objetivo apresentar a imagem ecológica do Papa Francisco a partir das considerações de Hans Belting, que afirma que cada ser humano é portador natural de imagens, fruto das suas experiências no tempo e no espaço. Cada pessoa é portadora natural, porque somente o ser humano consegue dar um sentido vivo às imagens. A partir dessa perspectiva, buscamos entender o Papa Francisco como um lugar de imagens, especificamente na perspectiva ecológica, considerando a importância do seu onomástico, Francisco, que em si já carrega uma imagem forte de uma representação de defesa da vida e de preservação do meio ambiente. Nesse sentido, consideramos também ser possível falar de um lugar antropológico da imagem ecológica do Papa Francisco.

Falar do Papa Francisco como um lugar de Imagens é considerar que cada ser humano se distingue um do outro justamente por causa das imagens que carrega em si, sejam elas internas ou externas. Nesse sentido, Francisco carrega em si a imagem do ser Papa; de Francisco, o santo; e as imagens próprias das suas experiências feitas no tempo e no espaço. São essas imagens que dão o tom da sua representação ecologista, principalmente no que diz respeito à imagem ecologista de Francisco, o santo, como ponto demarcador das ações do Papa na defesa da vida e do meio ambiente. A partir da renovação da imagem do santo, que havia perdido o seu espaço revolucionário no mundo, cedendo lugar apenas para a piedade popular, o Papa permite resgatar a foça e a coragem de alguém que muito lutou pela defesa da vida e do meio ambiente.

Dois momentos marcam significativamente a imagem ecologista do Papa Francisco. O primeiro foi com a publicação da Encíclica Laudato Si', sobre o cuidado da "casa comum", a fim de estabelecer um diálogo com toda a humanidade sobre a necessidade de se repensar o modo como nos relacionamos com o meio ambiente e com o meio humano. No entender do Papa, não há defesa do meio ambiente se não houver defesa do meio humano. O segundo momento foi quando, em 2017, o Papa convocou um sínodo para discutir, especificamente, a região Pan-Amazônica, um lugar com imagens e rostos próprios. A partir dessas motivações, o Papa deseja 
proporcionar, aos seus interlocutores, a experiência imagética de um lugar necessitado de cuidados de uma ressignificação ambiental, antropológica e política.

A partir da antropologia da imagem de Hans Belting, consideramos ser possível também falar de um lugar antropológico da imagem ecologista do Papa Francisco, considerando que a ecologia de Francisco visa construir um sentido vivo da imagem ecológica, a fim de criar no receptor uma proposta imagética diversa das imagens que só veem o meio ambiente como meio de exploração. Entretanto, para Francisco, não há defesa do meio ambiente se não houver defesa do meio humano, dois meios necessitados de atenção. Por isso ele defende que pensar a ecologia só é possível através de uma adequada antropologia, ou seja, a valorização de cada pessoa, para que todos se sintam comprometidos com a preservação do meio ambiente e do meio humano.

\section{PAPA FRANCISCO, UM LUGAR DAS IMAGENS}

"Cada ser humano é, naturalmente, um lugar das imagens" (BELTING, 2007, p. 71). Essa afirmação de Hans Belting coloca cada pessoa como portadora natural de imagens. Natural, não por qualquer motivo, mas porque "o ser humano é o único lugar onde as imagens recebem um sentido vivo" (BELTING, 2007, p. 71). Ou seja, o único lugar onde as imagens ganham sentido e significados próprios, por meio do seu portador natural. É essa característica de sentido natural das imagens que diferencia o ser humano de outros seres vivos, inclusive dos seus próprios semelhantes, porque "os seres humanos [também] se distinguem profundamente entre si, por causa das suas imagens" (BELTING, 2007, p. 72).

Nesse sentido, quando falamos do Papa Francisco, um lugar das imagens, estamos considerando a perspectiva beltingana que coloca cada pessoa como portadora natural das imagens. Ou seja, estamos falando de um corpo que além de ocupar um lugar no mundo, é capaz de criar e de reconhecer as imagens, a partir das experiências de vida feitas no tempo e no espaço (cf. BELTING, 2007, p. 72). Francisco é um papa latino-americano e, portanto, ele não poderia levar para Roma outra experiência se não as experiências próprias do seu contexto geográfico, latino- 
americano, especialmente do seu país de origem, a Argentina. Desse modo, Francisco é confirmado como um auctoritas[2] desterritorializado, uma voz decisiva no mundo (cf. CUDA, 2016, p. 48).

O Papa em si já carrega uma imagem que é própria do ser Papa, o representante da Igreja universal, a Igreja Católica. Quando um papa é eleito, o nome escolhido também já dá um indicativo das imagens que se estabelecerão no decorrer do seu pontificado. Nesse sentido, quando o então Cardeal argentino, Jorge Mário Bergoglio, foi eleito Papa, ao escolher o nome de Francisco, já estabeleceu uma imagem que é própria do santo, e que segundo ele é

um modelo belo e motivador. Tomei o seu nome por guia e inspiração, no momento da minha eleição para Bispo de Roma. Acho que Francisco é o exemplo por excelência do cuidado pelo que é frágil e por uma ecologia integral, vivida com alegria e autenticidade. É o santo padroeiro de todos os que estudam e trabalham no campo da ecologia, amado também por muitos que não são cristãos. Manifestou uma atenção particular pela criação de Deus e pelos mais pobres e abandonados. Amava e era amado pela sua alegria, a sua dedicação generosa, o seu coração universal. Era um místico e um peregrino que vivia com simplicidade e numa maravilhosa harmonia com Deus, com os outros, com a natureza e consigo mesmo. Nele se nota até que ponto são inseparáveis a preocupação pela natureza, a justiça para com os pobres, o empenhamento na sociedade e a paz interior (LS 10).

Nesse sentido, Francisco carrega em si a Imagem simbólica do ser Papa; de Francisco, o santo; e as imagens próprias das suas experiências de vida, no tempo e no espaço. Porque assim como os nossos corpos ocupam um lugar no mundo, nossos próprios corpos representam um lugar, através das imagens que captamos e que deixaram em nós uma marca invisível (cf. BELTING, 2007, p. 73. Imagens que foram configuradas através das percepções, ou seja, das "impressões diretas do mundo externo que nós apreendemos com nossos sentidos" (LOGAN, 2012, p. 70). Para Belting (2007, p. 73), a percepção é, evidentemente, uma operação analítica com a qual captamos os dados e estímulos visuais. É a partir da percepção que surgem as imagens como forma (Gestalt) (cf. BELTING, 2007, p. 73). Para Logan, as palavras são conceitos que abrangem as relações entre percepções, ou seja, as palavras representam conceitos e conceitos são representados por palavras (LOGAN, 2012, p. 
70). Contudo, Belting afirma que "as imagens têm vida própria e, portanto, não podem ser classificadas com um esquema histórico com conceitos rígidos" (BELTING, 2007, p. 75), porque estamos falando de processos dinâmicos, onde as imagens são transformadas, esquecidas, redescobertas ou ganham um novo significado (cf. BELTING, 2007, p. 74)

Entretanto, a partir da afirmação de Logan, que diz que "as palavras representam conceitos e conceitos são representados por palavras", podemos entender também que quando Bergoglio assume o homônimo de Francisco, ele não escolheu um simples nome, mas um conceito, um conceito dinâmico, chamado Francisco[3]. Mesmo porque, é essa imagem conceitual que dará a dinamicidade do seu pontificado, planejado e executado à luz das motivações da vida e do testemunho de São Francisco Assis, "o homem da pobreza, o homem da paz, o homem que ama e preserva a criação; ... é o homem que nos dá este espírito de paz, o homem pobre... Ah, como eu queria uma Igreja pobre e para os pobres!" (FRANCISCO, 2013), afirma Francisco. A imagem conceitual do Papa Francisco é a marca elementar de um pontificado, que além de um corpo natural representa um corpo coletivo, que está para além do ambiente eclesial, cristão. Desse modo, é possível compreender a preocupação do Papa com temas relevantes, que dizem respeito às várias problemáticas da vida humana, à luz da práxis testemunhal do santo.

Ao assumir o nome de Francisco, o papa ressignifica, portanto, aquele que foi um marco na história do cristianismo. Resgata a imagem de alguém que

sacudiu a religião, a civilização e a sociedade. Meio religioso, meio leigo, nas cidades em pleno desenvolvimento, nas estradas e no retiro solitário, no florescimento da civilização urbana combinado com uma nova prática da pobreza, da humildade e da palavra, à margem da Igreja mas sem cair na heresia, revoltado sem niilismo, ativo naquele ponto mais fervilhante da cristandade, a Itália central, entre Roma e a solidão de Alverne, Francisco desempenhou um papel decisivo no impulso das novas ordens mendicantes difundindo um apostolado voltado para a nova sociedade cristã, e enriqueceu a espiritualidade com uma dimensão ecológica que fez dele o criador de um sentimento medieval da natureza expresso na religião, na literatura e na arte. Modelo de um novo tipo de santidade centrado sobre o Cristo a ponto de se identificar com ele como o primeiro homem a receber os estigmas, Francisco foi 
uma das personagens mais impressionantes de seu tempo e, até hoje, da história medieval (LE GOFF, 2007, p. 9).

Se Francisco, o santo, havia perdido o seu espaço revolucionário no mundo, cedendo lugar apenas à prática da piedade cristã, quando o Papa assume o seu onomástico, o santo se renova e ganha um novo sentido na relação pessoal e coletiva $O$ santo sai da cristandade medieval para ganhar um novo significado no tempo e no espaço presente. Como diz Belting (2007, p. 86) "lugares que se recordam e pessoas que os recordam, são relações complementares". O Papa faz, portanto, uma nova experiência de Francisco, de um lugar cheio de significados e representações. Se as culturas, por exemplo, se renovam por meio do esquecimento, é por meio da recordação que elas se transformam (cf. BELTING, 2007, p. 84-85). Nesse sentido, ao recordar o santo, o Papa Francisco renova o espírito revolucionário daquele que "sacudiu a religião, a civilização e a sociedade" do seu tempo.

Uma das imagens marcantes do santo é sua imagem ecológica.

Francisco vê a criação inteira num estado de exaltação e louvor a Deus. Cada criatura louva o Criador por meio da beleza e do encanto que nela se manifestam e do elã vital que nela pulsa. O ser humano é convidado a respeitar a manifestação de Deus nas criaturas, e por intermédio delas louvá-lo. Ele não tem nada de próprio para oferecer em sua fragilidade, só pode bendizer e servir a Deus nas criaturas numa atitude de humildade e respeito. Para Francisco, é inconcebível um antropocentrismo de tipo moderno, porque o ser humano está inserido na natureza para reconhecer e respeitar nela a grandeza de Deus. Por isso, desenvolve um olhar de profunda admiração e respeito por cada ser criado, porque nele descobre a força de Deus (JUNGES, 2001, p.61).

Francisco assume a imagem ecológica do santo, como uma referência fundamental do seu pontificado. Na defesa do meio ambiente, o Papa se posiciona com fortes críticas ao sistema econômico, que segundo ele torna o meio ambiente indefeso face aos interesses do mercado divinizado (EG 56). O Papa busca, através da sua imagem simbólica, interpelar a humanidade acerca da necessidade da preservação, do que ele chama de "casa comum". Para Francisco, é necessário e urgente pensar uma ecologia integral. 


\section{A IMAGEM ECOLOGISTA DO PAPA FRANCISCO}

A ecologia é uma das imagens que tem um lugar especial no pontificado do Papa Francisco. É a expressão salutar de alguém que olha para além do contexto eclesial. Para Francisco, cuidar da fé é, antes de tudo, cuidar da vida, cuidar de cada pessoa, principalmente os mais pobres e esquecidos da sociedade. Nesse sentido, preservar o meio ambiente é, para o Papa, preservar a vida, é buscar o bem de tudo e de todos, porque "quem deseja viver com dignidade e em plenitude não tem outro caminho senão reconhecer o outro e buscar o seu bem" (EG 9).

\subsection{LAUDATO SI'}

Em 2015, terceiro ano do pontificado do Papa Francisco, ele lançou a Carta Encíclica Laudato Si' - Louvado sejas - sobre o cuidado da casa comum (LS). É nesse documento que o Papa manifesta sua preocupação com a preservação do meio ambiente. A partir da Laudato Si' a imagem ecologista do Papa toma forma, a fim de estabelecer um diálogo com toda a humanidade acerca da casa comum (LS 3). Com esse documento, o Papa lança um convite urgente para renovar o diálogo sobre a maneira como a humanidade está construindo o futuro do planeta. Para o Papa é necessário um debate que una a todos, porque o desafio ambiental que vivemos e as suas raízes humanas dizem respeito e têm impacto na vida de todos, indistintamente (LS 14). Para Passos (2016, p. 136-137), "a causa ecologista sensibiliza hoje boa parte do planeta e tem sido tratada pela academia como verdadeira questão disputada, sobretudo no que diz respeito à exortação das causas do chamado aquecimento global e das ideológicas do discurso da sustentabilidade".

Para Boff, por exemplo, sustentabilidade é uma questão de vida ou morte. Para o autor, "a sustentabilidade de uma sociedade se mede por sua capacidade de incluir a todos e garantir-Ihes os meios de uma vida suficiente e decente" (BOFF, 2016, p. 20). Na Laudato Si' o Papa fala de uma desigualdade planetária, ou seja, tanto o ambiente humano, quanto o ambiente natural estão se degradando em conjunto; e não é possível enfrentar adequadamente essa problemática, se não houver atenção especial às causas da degradação humana e social. Um problema de grande 
proporção e que, geralmente, recai com maior impacto sobre as pessoas mais pobres e vulneráveis da sociedade (Cf. LS 48). A esse respeito, o Papa "assinala que, muitas vezes, falta uma consciência clara dos problemas que afetam particularmente os excluídos. Estes são a maioria do planeta, milhares de milhões de pessoas [...], parece que os seus problemas são colocados como um apêndice" (LS 49), ou são tratados com propostas que não resolvem os seus problemas, mas que afetam diretamente o seu modo de viver, como por exemplo: a proposta da redução da natalidade (Cf. LS 50), que está ligada a um sistema capitalista, de concentração dos recursos nas mãos de poucos, que em vez de pensar um novo estilo de vida e de melhor distribuição dos recursos, prefere, numa atitude egoísta, roubar dos mais pobres o pouco que thes resta. Contudo, o Papa ressalta que "hoje, crentes e não crentes estão de acordo que a terra é essencialmente uma herança comum, cujos frutos devem beneficiar a todos" (LS 93).

A crise ecológica tem, na visão do Papa, uma raiz humana, que tem a ver com o poder da tecnologia que nos põe diante de uma encruzilhada, sendo fruto de dois séculos de mudanças, que possibilitou ao ser humano assumir um "poder" perante a vida em todas as suas dimensões. O Papa não critica o desenvolvimento tecnológico, ao contrário, reconhece todo o benefício que a tecnociência bem orientada pode proporcionar à melhoria da qualidade de vida do ser humano ${ }^{[4]}$ Aquilo com que o Papa não concorda é o fato de o imenso crescimento tecnológico, muitas vezes, não ser acompanhado de um desenvolvimento humano quanto à responsabilidade, aos valores, à consciência (Cf. LS 101-105). Nesse sentido, o Papa afirma que a humanidade "carece de uma ética sólida, uma cultura e uma espiritualidade que the ponham realmente um limite e a contenham dentro de um lúcido domínio de si" (LS 105). Conscientes de que cuidar do meio ambiente é responsabilidade de todos.

\subsection{SÍNODO PAN-AMAZÔNICO}

A partir das motivações da Laudato Si', o Papa estendeu as possibilidades de compreensão da sua imagem ecologista, direcionou o olhar para a região PanAmazônica, convocou um Sínodo especial para discutir as problemáticas da região, a fim de encontrar novos caminhos para a Igreja e para uma ecologia integral[5]. Um 
sínodo marcado por grandes debates, a favor e contra as motivações do Papa. Talvez porque a imagem sinodal tenha provocado uma operação analítica diversa em parte dos receptores, que não conseguiam fazer uma análise conjunta entre fé e sua relação direta com a preservação do meio ambiente. Um conflito interpretativo das imagens simbólicas em relação à práxis coletiva e as imagens pessoais (cf. BELTING, 2007, p. 75).

Ao colocar a Amazônia no centro das suas reflexões, o Papa não pretende se apoderar da imaginação nem dos sonhos de ninguém, como aconteceu em outros momentos da história (cf. BELTING, 2007, p. 76), mas apresentar um lugar geográfico, com imagens e rostos próprios. Dando a oportunidade para que se conheça um lugar por meio das imagens por ele manifestadas para que, a partir dessas imagens, se desenvolva uma práxis coletiva em relação às imagens pessoais. Porque "o mesmo lugar é contemplado com distintos olhos e por distintas gerações ou até mesmo por estranhos" (cf. BELTING, 2007, p. 80).

A Amazônia é um todo plurinacional interligado, um grande bioma partilhado por nove países: Brasil, Bolívia, Colômbia, Equador, Guiana, Perú, Suriname, Venezuela e Guiana Francesa. Todavia dirijo esta Exortação ao mundo inteiro. Faço-o, por um lado, para ajudar a despertar a estima e solicitude por esta terra, que também é "nossa", convidando-o a admirá-la e reconhece-la como um mistério sagrado; e, por outro, porque a atenção da Igreja às problemáticas deste território obriga-nos a retomar brevemente algumas questões que não devemos esquecer e que podem servir de inspiração para outras regiões da terra enfrentarem os seus próprios desafios (QA 5).

É, portanto, com o objetivo de despertar a estima e solicitude pela Amazônia que o Papa convida a humanidade a olhar para a Região, não com o olhar de exploradores, mas de protetores, pessoas que se preocupam com a vida e a preservação do Planeta. Para o Papa, a imagem que muitas vezes tentam passar da Amazônia, como uma região vazia que deve ser preenchida, como uma riqueza em estado bruto que deve ser aprimorada, ou como uma vastidão selvagem que precisa ser domada, não passa de uma falsa imagem, por não levar em consideração a vida das pessoas que vivem e dependem dos recursos naturais dessa região para sobreviver. Por vezes as vidas dessas pessoas são colocadas em segundo plano ou tratadas como intrusas ou 
obstáculos que precisam ser eliminados (cf. QA 12). Basta ver o modo como algumas políticas são estabelecidas, não importa o impacto da exploração, o importante é explorar e se aproveitar de todo recurso possível, independente das consequências que isso possa gerar.

Segundo Belting, (2007, p.79). "quanto mais se transformam os lugares em dimensões imaginárias, mais se apropriam das imagens que produzimos em nossos próprios corpos". Nesse sentido, transformar a região Amazônica em imagens, é permitir que os interlocutores possam fazer a experiência de um lugar mesmo que nunca tenham estado lá, a fim de que se possa construir, ainda que imageticamente, uma ideia de uma experiência real. Se para os adeptos da exploração inconsequente, a imagem que eles carregam em si é que explorar é um modo de gerar economia e fonte de renda, para o Papa essa imagem precisa ser ponderada, e por isso ele recorda o que disse o Papa Paulo VI, "os povos pobres ficam sempre pobres e os ricos tornam-se cada vez mais ricos" (QA 13).

\section{O LUGAR ANTROPOLÓGICO DA IMAGEM ECOLOGISTA DO PAPA FRANCISCO}

Para discutir o aspecto antropológico da imagem ecologista do Papa Francisco, partimos das considerações de Hans Belting, que afirma que é plenamente possível discutir o termo "antropologia da imagem", sem criar confusão ou dúvidas em relação ao termo com a disciplina existente, chamada "Antropologia" (BELTING, 2007, p. 9). Para Belting, a antropologia da imagem deseja revelar o verdadeiro ser humano, por meio da verdadeira significação imagética do mundo. Nesse sentido, quando o Papa Francisco chama a atenção da humanidade para as questões ecológicas, ele deseja criar no receptor uma proposta imagética viva e diversa às imagens inconsequentes e destruidoras da natureza e do ambiente humano, que colocam em risco a vida do Planeta. De modo que todos se sintam comprometidos com a construção de uma nova imagem ecológica e de respeito humano, a fim de desenvolver uma consciência cultural de preservação e de cuidado da "casa comum". 
O Papa Francisco afirma que "não há ecologia sem uma adequada antropologia" (LS 118), ou seja, não se pode discutir a ecologia de forma isolada da relação entre meio ambiente e meio humano. Por isso, o Papa Francisco insiste que, para exigir do ser humano um compromisso com o mundo, é necessário que ele seja também reconhecido e valorizado nas suas peculiaridades e capacidades de conhecimento, vontade, liberdade e responsabilidade (cf. LS 118). Em termos beltinganos, poderíamos dizer que não é possível estabelecer uma imagem ecológica adequada se esta não estiver intimamente relacionada com a valorização de cada pessoa em suas peculiaridades, a partir de suas experiências pessoais e coletivas:

O movimento ecológico mundial já percorreu um longo e rico caminho, tendo gerado numerosas agregações de cidadãos que ajudaram na consciencialização. Infelizmente, muitos esforços na busca de soluções concretas para a crise ambiental acabam, com frequência, frustrados não só pela recusa dos poderosos, mas também pelo desinteresse dos outros. As atitudes que dificultam os caminhos de solução, mesmo entre os crentes, vão da negação do problema à indiferença, à resignação acomodada ou à confiança cega nas soluções técnicas (LS 14).

É principalmente sobre essa indiferença humana que Francisco estabelece uma íntima relação entre o meio ambiente e o meio humano, dois meios, aparentemente distintos, mas intimamente dependentes um do outro. É fato que o meio ambiente não pode criar nem armazenar imagens do meio humano, porque essa é uma peculiaridade própria da condição natural do ser humano, a partir das suas experiências no tempo e no espaço. Entretanto, o ser humano é capaz de criar imagens tanto do meio ambiente, como do meio humano. É justamente sobre essa capacidade que se faz necessário entender a relação que existe entre as imagens que os corpos possuem dos lugares e das coisas, para não criar imagens "fictícias" ou "indiferentes" à realidade. Mesmo porque "os lugares na natureza só se transformam em imagem no espectador" (BELTING, 2007, p. 87), ou seja, naquele que faz a experiência dos lugares na natureza, seja de forma direta ou indireta, por meio das mediações.

Nesse sentido, podemos fazer uma distinção entre a imagem do grande empresário, dono de multinacional, que depende de matéria prima para que sua empresa continue 
a crescer e a lucrar cada vez mais, com a imagem do pequeno produtor ou de um nativo, que além de ter a natureza como o seu habitat natural, é também da natureza que ele tira o necessário para sobreviver. Para o grande empresário, explorar o meio ambiente é uma imagem natural, faz parte dos seus sonhos e projetos, independente das consequências que isso possa provocar. Ele não consegue carregar em si uma outra imagem que não seja a de explorador. Já o pequeno produtor ou o nativo, que depende verdadeiramente da natureza para sobreviver, sabe que quanto mais se degrada o meio ambiente, mais comprometido fica o meio humano, que sofrerá as consequências do descaso e de sua exploração inconsequente, porque a imagem que ele carrega em si é de uma interligação entre meio ambiente e meio humano, não havendo dissociação entre os dois. Nesse sentido, o Papa Francisco considera que,

tendo em conta que o ser humano também é uma criatura deste mundo, que tem direito a viver e ser feliz e, além disso, possui uma dignidade especial, não podemos deixar de considerar os efeitos da degradação ambiental, do modelo atual de desenvolvimento e da cultura do descarte sobre a vida das pessoas (LS 43).

A partir desse exemplo, podemos dizer que, proporcionar aos seus interlocutores uma nova experiência imagética, de um lugar marcado por uma diversidade de imagens, é o lugar antropológico do Papa Francisco, que coloca a vida humana como o ponto central da sua reflexão ecológica. Nesse sentido, o Papa afirma que "quando a pessoa humana é considerada apenas mais um ser entre outros, que provém de jogos do acaso ou de um determinismo físico, 'corre o risco de atenuar-se, nas consciências, a noção da responsabilidade"' (LS 118). O enfoque antropológico visa, portanto, devolver ao ser humano o lugar que lhe é próprio, o lugar vivo das imagens, a fim de construir uma consciência pessoal e coletiva de um lugar necessitado de uma nova significação imagética, e de responsabilidade com as imagens que se constroem a respeito do meio ambiente e do meio humano.

Outro ponto importante a ser considerado, é o que Belting diz a respeito das imagens pessoais e coletivas, ou seja, embora as imagens internas que carregamos nem sempre sejam de natureza individual, quando assumimos as imagens coletivas, estas passam a ser consideradas como se fossem próprias, de modo que perceber o mundo 
não é uma ação puramente isolada, mas também uma ação coletiva, predeterminada em cada época (cf. BELTING, 2007, p. 27). Isso para dizer, por exemplo, que se em outras épocas, explorar o meio ambiente era uma forma de acompanhar os avanços do mundo, hoje, essa forma de percepção já não se aplica mais. Por isso o Papa insiste na necessidade da assimilação de uma imagem do meio ambiente que esteja intimamente relacionada ao meio humano. Nesse sentido, quando se trata dos descasos em relação a esses dois meios, o Papa Francisco afirma que:

\begin{abstract}
estas situações provocam os gemidos da irmã terra, que se unem aos gemidos dos abandonados do mundo, com um lamento que reclama de nós outro rumo. Nunca maltratamos e ferimos a nossa casa comum como nos últimos dois séculos... O problema é que não dispomos ainda da cultura necessária para enfrentar esta crise e há necessidade de construir lideranças que tracem caminhos, procurando dar resposta às necessidades das gerações atuais, todos incluídos, sem prejudicar as gerações futuras. Torna-se indispensável criar um sistema normativo que inclua limites invioláveis e assegure a proteção dos ecossistemas, antes que as novas formas de poder derivadas do paradigma tecno-econômico acabem por arrasá-los não só com a política, mas também com a liberdade e a justiça (LS 51).
\end{abstract}

Um panorama propositivo, a fim de que o meio ambiente e o meio humano encontrem um novo lugar em nosso repositório pessoal de imagens. Ou seja, despojar-nos do corpo das imagens exteriores, para proporcionar-nos um novo corpo (cf. BELTING, 2007, p. 27), que esteja em sintonia com o momento atual. Mesmo porque,

vivemos com imagens e entendemos o mundo através das imagens. Uma relação viva que se estende de igual forma com a produção física de imagens que desenvolvemos no espaço social, seria o mesmo que dizer, o mundo se vincula com as imagens mentais da mesma forma que uma pergunta se vincula a uma resposta (BELTING, 2007, p. 14).

O fato de o corpo ser o lugar vivo das imagens, não significa que cada corpo seja independente uns dos outros, mas estão intimamente relacionados, através das experiências pessoais que se interligam com as experiências coletivas. As imagens mentais determinam o modo como cada pessoa vê e entende o mundo. Nesse sentido, quando o Papa Francisco propõe uma nova forma de ver e de se relacionar com o meio ambiente e com o meio humano, é porque deseja que cada pessoa possa reconstruir as imagens mentais relacionadas a esses dois ambientes, mesmo porque 
como afirma Belting (p. 69), "todas as imagens convocam continuamente à novas e distintas imagens".

Através da sua imagem ecologista, o Papa Francisco se apresenta como uma proposta imagética, que está para os receptores como um projeto de renovação por meio de uma nova experiência de vida, no tempo e no espaço. Mesmo porque, para o Papa, "o meio ambiente é um bem coletivo, patrimônio de toda a humanidade e responsabilidade de todos" (LS 95). Somente pela renovação imagética do meio ambiente e do meio humano será possível pensar uma nova ecologia, em que todos se sintam participantes e responsabilizados com a construção de uma nova imagem transformadora da vida e do mundo.

\section{CONSIDERAÇÃO FINAIS}

Apresentar a imagem ecologista do papa Francisco é considerar a significação imagética de um papa que é capaz de ultrapassar os muros do catolicismo para chegar a outros lugares, sejam eles geográficos ou lugares vivos, possibilitando aos receptores uma nova experiência no tempo e no espaço, a fim de oferecer uma gama de imagens que possam fazer parte do "acervo" imagético de cada corpo, na construção de uma nova maneira de ver e entender o mundo, a fim de que todos possam se comprometer com a preservação e o cuidado da "casa comum".

Se Francisco, o santo, revolucionou a Igreja e o mundo na Idade Média, Francisco, o Papa, ressignifica a força e o entusiasmo daquele que repensou a Imagem da Igreja, de dentro para fora e de fora para dentro. Por isso o Papa, ao assumir o onomástico de Francisco, assume o peso da imagem do santo que foi capaz de olhar a vida nos mínimos detalhes. Nesse sentido, o Papa nos permite hoje uma nova experiência de Francisco, o santo, a partir das suas motivações, como por exemplo, na defesa do meio ambiente.

É como se o Papa tivesse resgatado a imagem de Francisco de um museu, para nos permitir experimentar hoje a força e a vivacidade de um homem, que olhou para o meio ambiente com um olhar de filho e, portanto, de dependente dessa mesma 
natureza. Desse modo, o Papa coloca toda a humanidade envolvida num processo de ressignificação imagética, tanto do próprio santo, como das motivações do santo que norteiam hoje as motivações do Papa.

Para o Papa Francisco não há defesa do meio ambiente se não houver defesa do meio humano, dois meios conjugados que nos permitem falar de um lugar antropológico da imagem ecologista do Papa. Se Hans Belting considera ser possível falar de uma antropologia da imagem, pelo fato do ser humano ser o único corpo capaz de dar um sentido vivo às imagens, para o Papa, não há defesa do meio ambiente sem uma adequada antropologia, ou seja, não há defesa do meio ambiente se não houver defesa do meio humano, porque é este ser humano que dará um novo sentido vivo às imagens do meio ambiente. Portanto, pensar uma nova ecologia, é pensar uma nova imagem de ser e de estar no mundo.

\section{REFERÊNCIAS}

AUTORIDADE DO MAGISTÉRIO. In: Lexicon: dicionário teológico enciclopédico. São Paulo: Loyola, 2003.

BELTING, Hans. Antropologia de la imagen. Buenos Aires: Katz, 2007.

BOFF, Leonardo. Sustentabilidade: o que é - o que não é. Petrópolis: Vozes, 2018.

CUDA, Emilce. Para leer a Francisco: Teología, ética y política. Buenos Aires: Manantial, 2016.

FRANCISCO, Papa. Encontro com os representantes dos meios de comunicação social, 2013. Dispoível em: http://www.vatican.va/content/francesco/pt/speeches/2013/march/docum ents/papafrancesco_20130316_rappresentanti-media.html Acesso em: 31 de mai. de 2020.

FRANCISCO, Papa. Laudato Si' Louvado sejas: sobre o cuiddo da casa comum. São Paulo: Paulus e Loyola, 2015. 
FRANCISCO, Papa. Querida Amazônia: Ao povo de Deus e atodas as pessoas de boa vontade. São Paulo: Paulus, 2020.

JUNGES, José Roque. Ecologia e criação. São Paulo: Loyola, 2001.

LE GOFF, Jacques. Sao Francisco de Assis. Rio de Janeiro: Record, 2007.

LOGAN, Robert K. Infromação, linguagem e sua inter-relaçoa. In: Que é informação? A propagação da organização na biofesra, na simbolosfera, na tecnosfera e na econosfera. Rio de Janeiro: Editora PUC, 2012.

PASSOS, João Décio. A Igreja em saída e a casa comum: Francisco e os desafios da renovação. São Paulo: Paulinas, 2016.

\section{APÊNDICE - REFERÊNCIAS DE NOTA DE RODAPÉ}

2. Historicamente o termo "Magisterium", empregado para designar a função do papa e do episcopado é recente, tendo substituído o termo "auctoritas", de derivação plurissecular. Além disso, o vocábulo "Magisterium" é hoje acompanhado pela expressão "munus docendi" (LG 25), que se refere ao ensinamento em sentido estrito. É preciso, além disso, ter em mente que o conceito de "auctoritas", aplicado ao Sumo Pontífice e ao episcopado visto no seu conjunto, incluía sempre tanto a função de ensinamento como a função disciplinar. A partir do momento em que é introduzida a palavra "Magisterium" para indicar os mesmos assuntos, costuma-se admitir esta nova palavra para significar apenas a função de ensinamento. Portanto, é necessário lembrar que a autoridade na Igreja diz respeito tanto ao "munus tradendi doctrinam" (munus docendi) como à "potestas iurisdictionis", ou seja, à função propriamente de governo e disciplinar (munus regendi), como também à função de santificar mediante a sagrada liturgia (muniu sancrtficandi) (AUTORIDADE DO MAGISTÉRIO, 2003, p. $68)$.

3. Os conceitos permitem lidar com coisas que são remotas nas dimensões do tempo e espaço, tornando possível modelar o mundo externo e planejar (LOGAN, 2012, p. $70)$. 
4. Nesse sentido o Papa afirma que "é justo que nos alegremos com estes progressos e nos entusiasmemos à vista das amplas possibilidades que nos abrem estas novidades incessantes, porque 'a ciência e a tecnologia são um produto estupendo da criatividade humana que Deus nos deu"' (LS 101).

5. O Sínodo para a Amazônia foi convocado pelo Papa no dia 15 de outubro de 2017, para ser realizado em outubro de 2019.

Enviado: Agosto, 2020.

Aprovado: Agosto, 2020. 